\title{
Research on College English Online Teaching Design Based on Self-built Corpus
}

\author{
Tiannan Sun* \\ Changchun University of Technology, Changchun, China
}

\begin{abstract}
Based on the self-developed English language corpus and a series of College English micro courses, this study constructs College English online teaching platform, focus on a innovative design of college English online courses and try to test its teaching effectiveness. The results show that the corpus-based College English online curriculum design changes the traditional classroom teaching mode and teaching evaluation mode, promoting students' English level and autonomous learning ability, providing practical basis for the exploration of College English online teaching mode.
\end{abstract}

\section{Introduction}

At present, the development trend of College English teaching informatization has driven the exploration and research of new teaching methods, especially the prosperity and popularization of network teaching. In early 2020, Covid 19 was rampant, which had a great impact on normal school and classroom teaching in universities. During the epidemic period, the Ministry of Education issued the guidance on the organization and management of online teaching in Colleges and universities, requiring colleges and universities to actively carry out online teaching activities, so as to ensure the teaching progress and teaching quality. [1] As is known to all, colleges and universities have formulated relevant measures one after another, utilizing online platforms , MOOC resources ,micro classes and online live support, meanwhile, front-line teachers all over the country have adopted various ways to carry out online teaching to meet the needs, striving to learn new technologies by further professional training.

With the progress of mobile technology, the teaching and learning methods of English online courses have undergone changes, which contribute to the innovation of College English curriculum design. In this context, the author attempts to explore the construction of College English online curriculum from the perspective of self- built corpus. The corpus, based on computer technology and big data, which plays an increasingly significant part in second language learning, has been widely used in college English teaching. Its large-scale electronic text database provides a wide range of language materials for English learners. Although corpus research has made great progress in the past 10 years in Chinese second language teaching, it still has inadequate applied research on College English teaching.

* Corresponding author: 429081249@qq.com 
Therefore, in this paper, the author intends to introduce the self -built corpus into College English online teaching, explore how to establish a new model of online teaching driven by corpus data, find some problems and obstacles, and find corresponding countermeasures, which has certain value and significance for the construction of new college online classroom teaching in other universities. [2]

\section{Principles of the course design}

Online teaching environment offers the great flexibility and diversity of teachers' presentation of teaching contents .At present, most English Teaching in colleges and universities basically use the same set of teaching materials, which have served for a long cycle, out of touch with the times. New course design aims to enable teachers to teach students according to their aptitude and use corpus to guide their teaching practice. They can extract and build various corpora as their own teaching content according to their own teaching objectives and different students' English levels and learning needs. They can also establish or use parallel corpora or comparative corpora in relevant professional fields to carry out graded teaching practice. [3]

The available online teaching platforms can offer an intelligent educational environment. Through teachers' self -built corpus, a cloud classroom is constructed, which contains all digital media resources related to teaching materials. It supports comprehensive coverage before, during and after class, so as to meet the needs of personalized learning. In terms of teaching content, it supports the convenient use of resources in different parts of language learning. In the teaching mode, it supports the good interaction between the relevant subjects of teaching activities, and supports the reorganization and innovation of teaching process.

\section{Content and sources of the self- built corpus}

The self -built corpus will collect the materials from the major corpus for language learning corpus, such as American Contemporary English Corpus (COCA) [4], British National Corpus (BNC) [5], which are the largest free English Corpus in the world, including text novels, oral English, magazines, newspapers, academic articles and so on. They are updated regularly, and new words will be included, offering the learners authentic usage of the language. In addition ,some major corpus established for Chinese English learners will be sought for more suitable materials targeting college English teaching, such as Chinese Learner Corpus ,CLEC [6], College English learners' oral corpus ,COLSEC [7], HKUST (HongKong University Technology) Corpus Learner [8], English Chinese Parallel Concordancer (E-C Concord) [9], etc. Teachers are responsible for the retrieval of the corpus, collecting and sorting the materials, audios, videos or texts, selecting the parts to show the theme of the unit in novel and diverse technical forms, contributing to an effective acquiring of the language at the average college level.

\section{4 implementation of teaching process}

\subsection{Pre-class autonomous learning}

The design of online teaching mode will focus on learning centered classroom teaching and encourage students to carry out autonomous learning. Since the biggest problem of online autonomous learning comes from students' aimlessness and low efficiency, the teachers' 
self -built corpus provides sufficient, targeted and more effective digital resources after teachers' sorting and screening, which can ensure the needs of students' autonomous learning. Teachers devoted to constructing a specific assignment list for each unit ,so self built corpus containing reading, listening, speaking and writing practice for students' prevision will play a decisive role in the successful online course, while the current online course practice focus more on training students on the use of corpus platform and searching for the support for their assignment by themselves ,as we know, the operating of corpus software, such as extracting English thesaurus, lexical chunks, etc. ,tend to frustrate them instead because of the time spent on establishing a reference model so the corpus constructed by teachers will solve this problem and avoid confusing them about the teaching purpose. Students are required to complete their self- learning by sharing the digital curriculum resources, understanding the text, get the knowledge of background information and culture, watching and listening the videos and lectures of the native speakers ,particularly, learning the new words by heart . Thanks to the high-quality digital resources, students can be effectively well prepared for the class time.

\subsection{Online classroom teaching}

On the College English teaching platform based on self- built corpus, we construct a new classroom teaching model. Since teachers take it for granted that the students have finished self- education before class, the online class time will be mostly left for testing, analyzing and summarizing what the students have learned on their own to connect online interactive teaching and offline autonomous learning, finally form an organism of online classroom, achieving the purpose of improving students' self-study English ability and academic literacy.

In the process of online classroom teaching, teachers rely on the general network teaching platform, use the most basic functions, and take the individual teacher as the smallest user to implement teaching, which aims to realize the convenience and transparency of classroom management to achieve objective and comprehensive feedback by formative assessment. Students participate in learning more actively. As to the current available online teaching platform, the main functions supported include: instant check-in, in class test, classroom discussion (word cloud wall, bullet screen), cloud question bank and in class test, click answer, self-evaluation and mutual evaluation, courseware upload / download, student management, etc., enough to meet the needs of testing in the virtual classroom.

The content of the in- class test is divided into objective questions and subjective questions. The objective question part examines the basic knowledge of College English teaching, vocabulary, grammar, reading, listening and writing. The subjective question part can be used as a point of view collection, covering the cultural background and topic discussion related to the theme of the unit, and examining students' language application ability, oral English and point of view output. The materials of test questions and discussion topics will be collected by teachers relying on relevant corpora. The students will receive the result feedback of their own answers, and the teachers can also clearly see the answers of each student, which helps students improve their learning, teachers timely understand students' knowledge mastery, and strengthen the classroom interaction between teachers and students.

The students' active participation in the tests and group discussions depend on the complete system of formative teaching assessment. The new corpus -based online teaching system guarantees the implementation of process-oriented teaching evaluation. Teachers can evaluate and score students according to their rate of participation and correct answer in the feedback data. The objective scoring can not only make teachers easily realize the 
formative evaluation on teaching, but also avoid the disadvantages of traditional large class teaching, where teachers give the lectures and students are easily distracted. The class time will be devoted to questions and answers, which will greatly stimulate students' enthusiasm and attention, increase the interaction, and encourage students to better complete self-study before class. Teachers' comments and explanations on students' test and answer results are also a more effective way to summarize and throw light on the course content.

\section{Evaluation of teaching effect based on case study}

Since the biggest problem of E-learning is that the students have trouble concentrating on the lectures given by teachers, which leads to the low efficiency of class teaching, this design of the course is expected to eliminate the repetitive and fundamental parts from the teaching routine, promoting the students' autonomous learning ability, changing the role of the teachers .

In the spring semester of 2021, the author and her team, from Changchun University of Technology, conducted a comparative study of the college English online course based on self-built corpus in the three classes from School of Material Engineering .In one class, corpus based self - learning teaching mode was used, and the academic performance consists of final exam, which is the final test paper (40\%), and the daily performance (60\%). In the other two classes, we used conventional teaching which focus more on online classroom lectures and giving homework assignment. The final exam paper account for the biggest part of the total performance(70\%), while homework assignment, attendance and small quiz have $30 \%$.

The comparative study found that the overall level of final grade of students in the experimental class who used new teaching mode was significantly higher than that of the students studying in the traditional teaching, with the much higher excellence rate and pass rate .The comparison shows that self- educating assisted by the corpus built by their teachers is very important for improving students' academic achievement .Seen from the result ,the new course design arrangement promote the students' performance due to the improvement of students' learning motives. In the 1970s , American psychologist Bandura put forward the concept of self-efficacy, which refers to that individuals with a strong sense of self-efficacy tend to make more effort when facing setbacks, failures and difficulties. Bandura pointed out in his theory of motivation that human behavior is influenced by its result, which can stimulate and maintain the consistency of behavior to control and regulate human behavior. [10] For students, the result of their behavior in the classroom is their academic achievement, and the students' behavior is controlled by daily practice in the class time and daily performance they achieve. When the class time become a platform for them to display their talent, the questions from teachers become a great drive to stand out in a group, they have found the motivation in learning, encouraging them to develop a more sustainable way of learning language .

\section{Prospects for online College English Teaching with self- built corpus}

\subsection{The transformation of teachers' role}

The corpus based online classroom teaching model will promote the transformation of teachers from the center of teaching to impart knowledge to the guide for the students in learning knowledge. In this transformation, for one thing, the focus will be on how teachers 
can not only ensure students' autonomous learning to achieve the better effect of cultivating students' innovative thinking and practical ability, but also ensure students to master basic knowledge and discipline system, for another, the difficulty How to choose and control students' direction and mode in thinking is the in teaching. Therefore, different from the general idea of online teaching, this course classroom will build a convenient, efficient, fast and smooth communication platform between teachers and students. In terms of social space, the independently developed cloud platform is open and shared by the whole school, provides cyberspace services for each teacher and student and each course, and provides support for teacher and student discussion, homework Q \& A, collaborative learning, etc. Teachers timely and reasonably update the teaching methods and teaching progress according to the suggestions of students. In the process of interaction between teachers and students, students have some advantages, and teachers also benefit a lot. Only when teaching and learning grow together can we achieve good results. Teachers and students can call resources in resource space at any time; The teaching and interaction data of teachers and students in the classroom collected by intelligent devices can be uploaded to the social space at any time; In the social space, it can provide intelligent services such as learning situation diagnosis, learning planning and precision teaching based on big data. In addition, each teacher has a personal teaching space on the cloud integrated learning platform to provide rich curriculum teaching resources with self -built corpus. By logging in to the learning platform, students can freely choose teaching resources and learn anytime and anywhere outside the classroom. [11]

\subsection{Reform in College English Teaching evaluation system}

The self- built corpus assisted online teaching will use the new teaching evaluation system. Teaching evaluation has changed from result evaluation to the combination of result and process evaluation. The assessment results of students are mainly based on their usual results. The teachers make detailed records of students' usual learning conditions and provide the basis for their usual performance evaluation, which means that the classroom speech, after class discussion, homework inspection, thesis writing, experimental research, etc. in the learning process will become the basis for performance evaluation, so as to promote students to prepare carefully after class and take the initiative to think Actively speak and participate in discussion, mobilize students' learning enthusiasm, ensure that students' main energy is used for learning, and enhance the teaching effect of discussion class. [12]

\section{Conclusions}

This paper attempts to explore an innovative corpus assisted online teaching mode for college English courses at a general level .It deals with several modules of teaching, teaching cases and online teaching tools for the purpose of helping college teachers solve the real problems and puzzles they are facing in the implementation of online teaching. The problems may involve how to ensure the quality and effect of online classroom teaching, which is directly linked to sorting out and building a hybrid online teaching mode, integrating and utilizing teaching resources. Furthermore, the result of this paper will enable teachers effectively carry out the more creative teaching designs, organize learning interaction and monitor learning progress of online teaching. All in all, the rich resources in the available corpus will meet the actual needs of online teaching, promoting the long-term and sustainable development of college teachers' ability. The resulting self -built corpus can also be copied by other colleges and benefit the students on a larger scale. 
Grateful acknowledgement is made to my colleague Ms. Xiuwen Li who gave me considerable help by means of suggestion, comments and criticism. Her encouragement and unwavering support has sustained me through frustration and depression. Without her pushing me ahead, the completion of this thesis would be impossible. In addition, I deeply appreciate the contribution to this thesis made in various ways by my friends and students.

\section{References}

1. Jianli Jiao, Xiaoqing Zhou, et al: Case Study on Online Teaching of "Class Suspension without School Suspension" under the Background of Epidemic Prevention and Control, China Educational Technology (2020)

2. Nona Tollefson, Classroom Applications of Cognitive Theories of Motivation Educational Psychology Review (2000)

3. Teaching and Language Corpora [C]. London: Longman, (1997)

4. Mark Davies, Corpus of Contemporary American English(https://corpus.byu.edu/coca/) (2008)

5. British National Corpus (BNC) (http://www.natcorp.ox.ac.uk/ )(1993)

6. Gui, S./Yang, H. Chinese learner English corpus (CLEC), Shanghai Publishing House ( 2002)

7. Yang, H./Wei, N, College English learners' spoken English corpus (COLSEC), Shanghai Publishing House (2005)

8. HKUSTCorpus Learner, HongKong University Technology

9. Dr. Wang Lixun, Chris Greaves, English Chinese Parallel Concordancer (E-C Concord), The Hong Kong Institute of Education(http://ecconcord.ied.edu.hk/paraconc/index.htm)(1997)

10. Albert Bandura, Self-Efficacy - Toward A Unifying Theory Of Behavioral Change (1977)

11. Fubin Zhang, Guoqin Xu ,Network Teaching Quality and Teachers' Self-monitoring, Research on Continuing Education (2011)

12. Sinclair, J., Corpus Evidence in Language Description [R]. In A. Wichmann, S. Fligelstone, A. McEnery \& G. Knowles (eds.),(1997) 